\title{
La estructura de las ciudades españolas:
} un complejo entramado de relaciones

\section{entre permanencias y cambios, formas y usos}

\author{
The structure of Spanish cities: \\ a complex interweaving of continuity and change, uses and forms
}

\author{
Basilio Calderón Calderón \\ basilio@fyl.uva.es \\ José Luis García Cuesta \\ josgar@fyl.uva.es \\ Departamento de Geografía \\ Universidad de Valladolid (España)
}

\section{Resumen}

La rápida sucesión de paradigmas urbanísticos en las últimas décadas, ha contribuido a transformar la tradicional percepción de la estructura de la ciudad, de forma que es probable que no exista ya un formato único, que permita vertebrar las muchas piezas que animan la construcción dinámica del espacio urbano. En el presente artículo se presenta un esquema con el que poder interpretar el modelo de ciudad construido y remodelado tras dos décadas de práctica urbanística y acelerado crecimiento urbano (1996-2016). Se parte de la hipótesis de que una mayor densidad de episodios -boom y crisis- y elementos - vivienda, infraestructuras y equipamientos - vinculados a la nueva ciudad, hace necesaria una redefinición de los grandes rasgos de la estructura de una ciudad, en la que lo relevante no son ya los componentes, sino el modo de estar relacionadas las distintas partes del conjunto urbano.

Palabras clave: ciudad; estructura urbana; viviendas; España. 


\begin{abstract}
The quick succession of urban paradigms over the last few decades has contributed to the transformation in the traditional perception of the structure of the city, so it is probable that there is no longer a single, unique format that can allow us to fit together the many pieces that make up the dynamic construction of the urban space. This current article presents a scheme with which to interpret the city model, built up and rebuilt after two decades of urban practice and accelerated urban growth (1996-2016). The article is based on the hypothesis that a greater density of episodes (boom and crisis) and elements (housing, infrastructures and facilities) linked to the new city makes it necessary to redefine the major characteristics of the city's structure, in which what is relevant is no longer the components, but the way in which the different parts of the urban set are related.
\end{abstract}

Key words: city; urban structure; housing; Spain.

\title{
1 Una hipótesis para interpretar los grandes rasgos de la estructura de las ciudades españolas
}

Desde hace algunas décadas, el análisis geográfico de la ciudad, y en particular de la estructura urbana, ya no puede tener al carácter finalista y regular que tuvo en el pasado, y que permitía agrupar primero y separar después, porciones de territorio urbano en función de combinaciones demográficas, sociales, morfológicas y funcionales, predecibles e intercambiables dentro del sistema, dada la estabilidad de las relaciones y flujos que hilvanaban el tejido urbano. Esa forma de entender la estructura de la ciudad, contemplaba sus elementos integrantes como un conjunto estático y predecible a partir de su disposición -coronas, aureolas, sectores-, y no del "modo de estar relacionadas las distintas partes de un conjunto", conforme la segunda acepción del término estructura del Diccionario de la Lengua Española. Así entendido, el concepto de estructura hace referencia no solo a elementos físicos de carácter estructural, sino también a las relaciones funcionales a que obliga la localización de los diferentes usos del suelo y el carácter global, compartido y totalizador de algunos de ellos (Kagermeier, 2007).

En este sentido, puede no ser suficiente la simple búsqueda de regularidades a partir de variables objetivas y controladas como la población, superficie, densidad, actividad, o una combinación de algunas de ellas, con la finalidad de compartimentar el espacio en unidades abarcables y controlar la intervención o la distribución de servicios o equipamientos en el espacio urbano. Los cambios que ha experimentado la ciudad en las últimas décadas han desdibujado aquella supuesta imagen estática de los componentes de una estructura urbana, de tal modo que ya no hay un formato único, comúnmente admitido, que permita entender la interrelación de las muchas piezas que animan la construcción dinámica del espacio urbano; ni aun considerando el carácter dominante, 
que no exclusivo, que deben tener las actividades o elementos integrantes de un área para poder individualizarla y diferenciarla en el entramado morfológico, funcional o social de una ciudad.

Conscientes de esta situación, planteamos como hipótesis, que el agregado de actividades vinculadas o próximas en la tipología y uso del suelo, que fue el criterio dominante en el pasado, debe combinarse con lo que a nuestro juicio son factores determinantes en el sistema operativo de una ciudad, es decir, en el conjunto de elementos o áreas que realizan funciones básicas en la identificación y percepción de cada fragmento de la ciudad, y permiten entender la composición y comunicación con y entre otros elementos de la misma. Este papel está reservado a aquellos hechos que anclan la percepción urbana en torno a lugares comunes y rutinas predecibles, así como a la forma en que se relacionan con ellos, movilidad mediante, el resto de los componentes de la ciudad o área urbana en su conjunto. De este modo, la forma y carácter de cada lugar, definido por sus atributos emergentes, las condiciones de su momento creador, la diversidad de sus usos, los vacíos urbanos - permanentes o coyunturales- y las infraestructuras y pautas de movilidad, serían alguno de los factores que pueden conformar la percepción de los componentes básicos de una ciudad y de sus relaciones, a la que tradicionalmente hemos identificado como una estructura.

Para tratar de demostrar esta hipótesis se ha realizado una reflexión, de carácter morfogenético, apoyada en el uso de la información gráfica y estadística disponible, y en las aportaciones geográficas más recientes en este campo, con objeto de ofrecer un esquema con el que poder interpretar el modelo de ciudad heredado tras dos décadas de práctica urbanística y acelerado crecimiento urbano (1996-2016). Se ha realizado una interpretación metodológica apoyada en valoraciones históricas, sociológicas y morfológicas, por entender que son las que permiten llevar a cabo una primera aproximación a las relaciones entre elementos heterogéneos, la forma en que aparecen agregados, conformando grandes áreas con un status derivado de la singularidad de su momento creador y de la accidentada evolución de los últimos años -extensiones vs reforma interior-.

Con este objeto se han consultado las principales aportaciones hechas en el siglo XXI por geógrafos en algunas de las revistas con mayor penetración en la investigación geográfica -Boletín de la Asociación de Geógrafos Españoles, Scripta Nova, Estudios Geográficos, Investigaciones Geográficas, Cuadernos de Geografía, Anales de Geografía, Documents d'Anàlisi Geogràfica, Eria o Polígonos, entre otras-; y se han revisado, asimismo, las últimas publicaciones del Grupo de Geografía Urbana de la Asociación de Geógrafos Españoles, y en particular "Espacios y paisajes urbanos: reflexionar sobre su presente para proyectar el futuro" (2010), "Las ciudades y el sistema urbano. Reflexiones en tiempos de crisis" (2012), y "Territorios inconclusos y sociedades rotas" (2016). 
Se ha explotado información procedente de diversas bases de datos oficiales, alojadas en el portal del Ministerio de Fomento. Se han analizado, asimismo, las bases de datos del INE -Censos de Población y Viviendas 2011-, así como la información del Atlas Estadístico de las Áreas Urbanas en España, del Sistema de Información Urbana 2016, del Observatorio de Vivienda y Suelo, del Observatorio de la Vulnerabilidad Urbana -y singularmente los atlas de la vulnerabilidad urbana 2001 y 2011-. Se ha consultado, asimismo, el informe sobre la situación actual de ámbitos o sectores con especial potencialidad edificatoria incluidos en el Sistema de Información Urbana (SIU): Áreas Urbanas +50, Paisajes 20x50 (20 paisajes en 50 años), Sectores Residenciales 2014, "Capitales\&Ciudades+100, información estadística de las ciudades españolas 2010 (Ministerio de Fomento, 2017a). En el mismo sentido y para documentar determinados aspectos del mercado inmobiliario residencial, se han revisado las bases de datos del Ministerio de Fomento sobre Vivienda protegida, Vivienda libre, Estimación del parque de viviendas, stock de vivienda nueva, Transacciones inmobiliarias (compraventa), Valor tasado de la vivienda y sobre los Precios de suelo urbano (Ministerio de Fomento, 2017b).

Para realizar una primera aproximación a la morfología de los tres grandes conjuntos señalados, es decir, la ciudad centro, la ciudad polígono y la ciudad periferia, se han consultado los Servicios Web de Mapas (WMS) que ofrece el Ministerio de Fomento a través de la denominada Infraestructura de Datos Espaciales (IDE), derivada de la Directiva comunitaria Inspire 2007/2/EC. En particular, se ha tomado como referencia el Servicio WMS del Sistema de Información de Ocupación de Suelo de España (SIOSE) 2005 y 2011 y CORINE Land Cover (1990, 2000, 2006 y 2012) que ofrece el Instituto Geográfico Nacional y que está desarrollado conforme a las especificaciones de la Directiva Inspire (Ministerio de Fomento, 2010).

\section{La estructura urbana como suma de percepciones de ciudad: transversalidad, vacíos y flujos}

Es un hecho demostrado que la vieja ciudad española de estructura sencilla, de centro y arrabales, de intramuros y extrarradios, de campo y ciudad con límites casi absolutos (García Fernández, 1974, 2000) ha sido reemplazada, al compás del vertiginoso crecimiento y cambio urbano de las últimas décadas, no tanto por una nueva estructura, sino por ciudades con muchas estructuras repetidas; ciudades en las que la diferencia viene determinada por la relativa experiencia de ciudad que cada una de ellas ofrece. Dicho de otra manera, muchos de los fragmentos en los que ha estallado la vieja ciudad compacta, son piezas de una ciudad mayor, de un área urbana más extensa dentro de la que se vive, en la que se observan hábitos y comportamientos urbanos, pero que ninguna de ellas proporciona una experiencia completa de ciudad. Los elementos que componen este puzle son suficientemente conocidos, y han sido analizados por algunos autores (Campesino, 2014; Precedo \& Mínguez, 2014; Brandis, 2007; Nel.lo, 1998; Mała, 2007; Lois, 
2016; Burriel, 2008) ${ }^{1}$ que vienen a destacar las constantes en torno a la movilidad urbana especialmente interesante en el contexto de expansión y crisis de las dos últimas décadas-, a la tipología y redistribución funcional de las viejas y nuevas periferias, al significado de los nuevos polígonos residenciales o industriales, al papel de las grandes infraestructuras y equipamientos $y$, singularmente, a la progresiva tendencia de las estructuras urbanas hacia el policentrismo, habida cuenta que "se ha roto, sin duda, el paradigma de las ciudades monocéntricas, estructuradas en torno a un único CBD" (Roca \& Arellano, 2012).

Otros autores (Delgado \& García, 2009) han realizado una sugerente aproximación al concepto de los cambios en la ciudad a partir de la consideración de los nuevos paisajes de la ciudad global, entendida en los términos que nosotros hemos definido como ciudad periferia. Los atributos asociados a este inacabado tercer sector de la estructura de la ciudad se interpretan en términos de confusión, provisionalidad, estandarización, aterritorialidad, y pasan a ser determinantes en la percepción de la ciudad de las tres coronas - suburbana, periurbana y rururbana- según el clásico axioma de las pautas de crecimiento regular de los bordes urbanos, frente a lo que los autores identifican como núcleo central. Estas y otras interpretaciones hechas a partir de la identificación de texturas urbanas, confirman la gradual pérdida de referentes urbanos y la necesidad de volver a enraizarlos en un lugar con capacidad para totalizar toda su experiencia y memoria.

En todos ellos se destaca el papel que tienen, en la estructura de las ciudades españolas, los elementos clásicos de análisis, ya sean centros vs periferias, barrios degradados vs barrios acomodados, áreas residenciales vs áreas dotacionales, o el papel de los centros de la administración como impulsores de nuevas áreas de centralidad, especialización y cualificación residencial (Calderón \& García Cuesta, 2014). Con ello, se confirma que la actividad en una ciudad se organiza en muchos ámbitos separados entre sí, generalmente pareados, de forma que cada residente o usuario carece de la experiencia de todos los demás fragmentos, que no ve, que visitará ocasionalmente y que le son completamente ajenos, careciendo de la percepción completa de una ciudad. Contemplada desde esta perspectiva, es probable que la estructura de la ciudad se pueda entender mejor a partir de las redes y flujos que la animan, y de los grandes polos de atracción o de centralidad sobrevenida, que de los paquetes o agregados de percepción dominante que tradicionalmente habían servido para diferenciar, por ejemplo, un barrio periférico denominado obrero, del centro considerado burgués.

Sobresalen en este contexto los numerosos estudios que se ocupan de los dos fenómenos más relevantes en las décadas del cambio de siglo: la expansión urbana y la rehabilitación y regeneración de la ciudad tradicional -centro y barrios históricos-. De entre los primeros, cabe

1 La relación de autores que han realizado aportaciones sobre esta materia es considerable, mereciendo una especial consideración los vinculados al Grupo de Geografía Urbana de la Asociación de Geógrafos Españoles (AGE). 
mencionar el carácter de síntesis que tiene la obra de Marchena y Hernández (2016) sobre la ciudad de Sevilla, o el estudio de Santos Preciado (2016), que aporta una atractiva metodología para medir la estructura urbana de la ciudad actual a partir de la base de datos del catastro y la tipología constructiva unifamiliar dominante en la ciudad periferia; en similar sentido, aunque con otras metodologías, se orientan los estudios de Fernández (2003) sobre las pautas de crecimiento urbano postindustrial, de Cebrián (2007) sobre las manifestaciones de la ciudad difusa en Castilla La Mancha, o de Ponce (2013) sobre las estrategias de metropolización de la ciudad de Valencia. Especial mención merece el estudio del año 2014 de Soria-Lara y Valenzuela (2014) sobre el binomio "estructura urbana-patrón de viaje" que se ha ido afianzando como consecuencia del aumento del número de desplazamientos y uso del automóvil en áreas urbanas durante las últimas décadas, y que se ha resuelto en la proliferación de numerosos estudios acerca de los factores de la estructura urbana que tienen influencia en la elección del modo de transporte, o cómo la estructura urbana condiciona la demanda de viajes.

La estrategia de crecimiento desplegada tras la Ley sobre régimen de suelo y valoraciones, contribuyó a transformar radicalmente la ciudad (Roca, 2011; Nel.lo, 1998; Mas, 1999; López de Lucio, 2004; Fernández, 2003) a tal punto que "la expansión del modelo difuso de ciudad, junto con la intensificación y diversificación de los procesos de urbanización, hace difícil utilizar la definición urbanística o morfológica de ciudad como unidad básica del análisis" (Salom, 2011). En función de ello, y en el marco de las nuevas y extensas conurbaciones, resulta arriesgado considerar la ciudad como un polo único que articula el territorio circundante; antes al contrario, es necesario tener en cuenta la existencia de flujos cruzados en el interior de las áreas urbanas, o lo que es lo mismo, de multitud de relaciones entre los nodos que las vertebran, sean de especialización ultraresidencial, ultraindustrial o ultradotacional, y que pese a su relevancia, carecen de la experiencia de ciudad como el espacio casi aterritorial que lo contiene todo, que carece de los límites - principio y fin- en los que los análisis geográficos habían anclado tradicionalmente su relato.

Una importancia creciente empiezan a tenerla los estudios sobre lo que podemos denominar la vuelta al centro, vinculados por lo general al nuevo paradigma rehabilitador-regenerador que consagra la Ley de Suelo de 2007; en unos casos, el modelo está vinculado a los procesos de gentrificación, como han estudiado Diaz (2014) o Alba (2001), resaltando el carácter dual de sus resultados, ya que suelen coexistir áreas renovadas y áreas sometidas a procesos de tugurización, como sucede en el caso de Barcelona (Raval). Otros autores, contemplan este proceso de forma integral, es decir, partiendo de la hipótesis de la quiebra del modelo de ciudad que contiene el centro urbano, puesta de manifiesto en la pérdida de las funciones tradicionales -industria o residencia-, para ser reemplazadas por otras con mayor necesidad de centralidad, aprovechando 
las oportunidades que abrieron en su día algunos instrumentos de teórica protección como fueron los Catálogos de los Planes Generales de Ordenación Urbana (Álvarez Mora, 2016).

Una síntesis de referencia sobre estructura urbana es la que realiza $H$. Capel, a propósito de unas reflexiones acerca de los caracteres y problemas de ciudad en general y sobre la ciudad postcapitalista en particular, abordados desde tres perspectivas: la de la ciudad física construida con su morfología - lo que los romanos llamaban la urbs-, la ciudad de los ciudadanos y sus comportamientos - la civitas-, y la organización administrativa y política -la polis- (Capel, 2016, p. 10). Y en el mismo sentido resultan especialmente relevantes las aportaciones realizadas en el XII Coloquio del Grupo de Geografía Urbana de la Asociación de Geógrafos Españoles, publicadas con el sugerente título de "Estudios de Geografía Urbana en tiempos de crisis. Territorios inconclusos y sociedades rotas en España" (Brandis, Del Río \& Morales, 2016).

En términos generales, toda la literatura científica sobre esta materia, abunda en la idea de que la ciudad ha dejado de ser aquel agregado estable, predecible, en el que todos sus elementos se ordenaban siguiendo viejos e inmutables principios de mercado, o viejas pautas de asignación institucional de población y usos, en las múltiples variantes de polígono, tradicionalmente ordenados por usos - residenciales, industriales, deportivos, dotacionales etc.- o más recientemente, y en las nuevas periferias, por la figura de planeamiento o de gestión urbana que los dibuja: planes parciales, planes especiales, programas de actuación urbanística, sectores, unidades de actuación, etc. Por el contrario, la ciudad puede entenderse como una suma de desagregados espaciales, de uso habitual, ocasionalmente agregados siguiendo pautas de desplazamiento y de consumo del tiempo diario-semanal-estacional propias de la ciudad de principios del siglo XXI.

Y es que, la esencia de la ciudad tradicional, se encuentra en las múltiples experiencias de vida y de ciudad que pudo proporcionar, ya que se mantenía con ella una relación cercana, íntima. Queremos a la ciudad cuando podemos conectar con ella de manera íntima y sumar recuerdos conformados a escala del peatón (Salingaros, 2005). Pero la ciudad actual ha eliminado en gran medida esa experiencia al subordinar toda la ordenación espacial al uso del automóvil; y lo que se formó con ese criterio, estaba adaptado a la escala y conexiones de una ciudad hecha por polígonos, es decir, por nodos de semejantes, de innecesaria e imposible complementariedad y conectividad hasta conformar, especialmente en la segunda mitad del siglo XX, vastas porciones de ciudad despersonalizadas, a la que hemos denominado ciudad polígono, ya esté conformada por vivienda sin nodos comerciales, oficinas sin viviendas, industria sin residencia, y así sucesivamente.

$Y$ es que, si consideramos que las fuerzas que permiten que la ciudad funcione son generadas por la diversidad y la necesidad de intercambio de información entre nodos de diferentes tipos, carece de sentido agrupar físicamente nodos del mismo tipo en un área geográfica ya que no habría conectividad, necesidad de relación e intercambio de información. Todo el tejido que envuelve a la 
ciudad tradicional en España y en Europa en general, fue concebido en este ideal antifractal, estandarizado y regular que hace tan compleja su integración y reforma en el presente. Y, en la misma dirección, el proceso de reforma de los centros de las ciudades se ha amoldado a una nueva estrategia, según la cual, el centro se ha convertido en un nodo más -el mismo en todas las ciudades- perdiéndose con ello el carácter fractal, es decir, roto, fragmentado, singular y diverso que tuvo en el pasado.

Pero, sea cual sea la forma de entender su estructura, toda ciudad está construida a partir de elementos tan rutinarios que necesita espacios de fuga en los que escapar de la distopía uniforme en la que la sociedad y la ciudad están instaladas. Son porciones de ciudad a las que el imaginario social ha atribuido alguna virtud imposible de encontrar en cada escenario vital cotidiano, pero que forman parte del modo habitual de escapar de la rutina vital, acondicionándose de forma espontánea o inducida para cumplir esta nueva función urbana: barrios-museo, ciudad de experiencias, fragmentos de ciudad para grupos de nueva transversalidad, ciudad de la cultura, paseos por la historia, o memoria de natalicios, obituarios y batallas; y también nuevas reservas urbanas, lugares donde acotar una experiencia singular, lugares capaces de proporcionar al usuario ocasional o al nuevo usuario permanente, la experiencia de ciudad perdida; y por ello también lugares de imposible encaje en los paradigmas de la estructura urbana convencional, tal y como se ha venido abordando por parte de la Geografía, de la Sociología o la Ecología Humana desde principios del siglo XX (Delgado, 2016).

Entendemos por ello la estructura de la ciudad como una suma de transversalidades, de fragmentos que en su día quisieron ser ciudad completa, de percepciones de la realidad capaces de asentarse en el imaginario colectivo, como lugares que, sumados, conforman la experiencia de ciudad, imposible ya de alcanzar en la escala personal e incluso colectiva, en la era de la ciudad global. Esta ciudad, anónima por sus dimensiones y relaciones, necesita de la experiencia que proporciona la recuperación ocasional del espacio perdido, ya sea real o simulado, toda vez que cada porción de un espacio urbano, ha dejado de ser aquél lugar en el que se está y que "contiene", para convertirse en un lugar al que se va o por el que se pasa, para adquirir, ocasionalmente, una determinada experiencia de ciudad o participar en un agregado de relaciones imposibles en la vida cotidiana, y efímeras por su excepcionalidad, como la que proporcionan los nuevos centros comerciales ubicados en sus periferias.

Para ordenar el agregado de formas y relaciones señaladas, las ciudades españolas han dispuesto de un ingente caudal normativo, extremadamente sensible al cambio político, y por lo tanto generador de incertidumbre, que en la práctica ha hecho laberíntica la gestión urbanística, obligada a sortear decenas de procedimientos administrativos y competencias a veces encontradas entre las múltiples administraciones implicadas en lo que algunos autores han denominado el desgobierno territorial (Campesino, 2014). Con tan cambiante marco legal, y tras casi tres décadas 
de políticas y planes, no se ha dispuesto de un proyecto estable de ciudad, indiferente a las modas o a las coyunturas, con el que evitar la sucesión de ciclos en los que de alguna forma se maximiza la escasez para mantener operativo el sistema de reproducción del sistema inmobiliario (Calderón, 2012). De esta forma, el modelo de intervención dominante en este periodo ha sido siempre remedial, cíclico y confiscatorio. En unos casos, para atender la escasez de oferta, en otros, para ensanchar la base de la demanda solvente, y en otros más, para asegurar en torno al producto inmobiliario una muy alta e insaciable fiscalidad local, regional y estatal, como constatación de una evidencia: que en realidad la propia ciudad es el negocio.

Los efectos que en la estructura ha tenido la vertiginosa sucesión de paradigmas (ver Tabla 1), han venido a consolidar el peso y relevancia que en cada momento tienen los tres grandes conjuntos en los que hemos articulado esta interpretación sobre la estructura de las ciudades españolas: en primer lugar, el centro y ciudad tradicional en general, que mudan de carácter funcional tras verse privados de su base demográfica y estructura social, y que vacía o rellena su tejido en función del paradigma dominante; en segundo lugar, la ciudad relleno o polígono, que conforma gran parte del espacio edificado y que, por sus dimensiones y composición, constituye el paisaje formal del grueso de la población urbana.

Tabla 1. Cambios de paradigma e impacto en la dinámica urbana

\begin{tabular}{|c|c|c|}
\hline SUCESO & PARADIGMA & DINÁMICA \\
\hline $\begin{array}{l}\text { 1998-2006: } \\
\text { Ley Régimen de Suelo y } \\
\text { Valoraciones }\end{array}$ & $\begin{array}{l}\text {-Desarrollo de normativa autonómica } \\
\text {-Construir y vender: boom inmobiliario } \\
\text { (1998-2007) }\end{array}$ & $\begin{array}{l}\text {-Hipercrecimiento del suelo } \\
\text { urbanizable } \\
\text {-Del polígono a la periferia }\end{array}$ \\
\hline $\begin{array}{l}\text { 2007-2014: } \\
\text { Ley de Suelo }\end{array}$ & $\begin{array}{l}\text {-Crisis financiera e inmobiliaria. } \\
\text {-Adaptación de la legislación urbanística } \\
\text { regional } \\
\text {-Sostenibilidad y Regeneración }\end{array}$ & $\begin{array}{l}\text {-Congelación y reversibilidad } \\
\text { del suelo urbanizable } \\
\text {-De la periferia a la ciudad } \\
\text { polígono }\end{array}$ \\
\hline $\begin{array}{l}2015 \\
\text { T.R. de la Ley de Suelo } \\
\text { y Rehabilitación Urbana }\end{array}$ & $\begin{array}{l}\text {-Estrategia de las cuatro " } R^{\prime \prime} \text { : } \\
\text { rehabilitación, regeneración renovación y } \\
\text { reventa } \\
\text {-Tercera generación de la legislación } \\
\text { regional }\end{array}$ & $\begin{array}{l}\text {-Fin de la expansión indefinida. } \\
\text { - Regeneración: del polígono al } \\
\text { centro }\end{array}$ \\
\hline
\end{tabular}

Fuente: elaboración propia

Se trata, en efecto, de un espacio heterogéneo, suma de una considerable relación de actividades, pero carente de espacios y funciones con capacidad para afianzar el tradicional sentimiento de pertenencia a la ciudad como un todo. Este sector, que se comenzó a vaciar en los años noventa del siglo XX para llenar la periferia, siguiendo el clásico esquema de invasión-sucesión, mantiene vacíos estratégicos, temporalmente ocupados por grupos de población subintegrada, que convierte en vulnerables a barrios en origen bien integrados. Y, finalmente, la ciudad periferia, una porción de ciudad a medio llenar, y tan perfectamente planificada y ordenada en su interior -resultado de 
decenas de planes parciales yuxtapuestos - como fragmentada, incompleta, llena de vacíos, y por tanto, privada del carácter de ciudad que sólo se obtiene en combinación con la experiencia que proporcionan otros fragmentos (barrios) de la ciudad.

\section{El centro o ciudad tradicional como síntesis de toda la experiencia urbana: una parte por el todo}

Como herederas de una tradición compartida, cosida por decenas de leyes y normas urbanísticas, por miles de ordenanzas municipales, y centenares de planes generales de ordenación, es evidente que las ciudades españolas han de presentar unos rasgos comunes en la disposición e incluso relación de sus elementos. La estructura resultante, pese a los cambios habidos en los últimos años del siglo XX, sigue vertebrándose a partir de lo que podemos identificar como ciudad tradicional, es decir, su parcialmente intervenido centro histórico, arrabales en su caso, su ensanche o crecimiento equivalente, y sus barrios extrarradio decimonónicos. Todos ellos están afectados, aunque en medida diversa, por procesos de pérdida selectiva de población y de renovación, rehabilitación o restauración, impulsados en algunos casos por la administración o derivados del dinamismo funcional arraigado en algunas de sus calles; ${ }^{2}$ y ambos procesos coexisten con la resistencia al cambio de algunas bolsas de deterioro morfológico y social, de presencia cada vez menos notable, al haberse desviado una parte de los procesos de tugurización hacia los barrios obreros de la primera periferia del centro, construidos en los años cincuenta y sesenta (Calderón, 2003).

Esta ciudad tradicional es un sector muy complejo y sensible al cambio, en el que se pueden identificar diversos subsectores, atendiendo a su perfil funcional que, perdida su identidad vernácula, se identifican ahora a partir de elementos comunes en el paisaje que tienen la virtud de convertir lo diverso y local en semejante y universal; y también a partir de pautas de uso del espacio agrupadas en dos grandes categorías: el día y la noche. Gran parte de estos nuevos subcentros del centro, son en realidad espacios de monocultivo, ya sean áreas hiperespecializadas en restauración, estrechamente vinculadas a la explotación turística del patrimonio arquitectónico, frente a barrios en los que la función dominante es la explotación del ocio nocturno; y también algunos pequeños distritos comerciales - a veces una calle o algunas manzanas etiquetadas como millas de oro- agrupados en torno a determinadas franquicias locomotoras en el sector textil, calzado y en general equipamiento personal y del hogar. No menos importante es el centro de negocios, en el que se concentra la actividad profesional, la administración y la banca, anclado en

2 "El cuerpo de la ciudad no puede ser ni física, ni socialmente una masa acéfala. La ciudad, cuerpo vivo y organizado, material y espiritualmente debe tener cabeza y corazón. Esa cabeza y a un tiempo corazón de la ciudad es el centro cívico, complejo de espacios y edificios que sirve de punto focal a las actividades sociales de la urbe y de lugar de reunión en el cual los ciudadanos pueden hallar ocasiones frecuentes de estrecharse las manos, de escoger libremente el tema de conversación." (Sert, citado en Alomar, 1961, p. 120). 
los ensanches o en aquella porción más o menos relevante de la ciudad burguesa levantada en el siglo XIX.

Finalmente, la composición de los centros se completa con aquellas áreas sometidas a procesos de abandono y degradación y convertidas de facto en tejido de reserva, en las que se interviene de forma ocasional mediante ambiciosos programas de regeneración integral, por iniciativa institucional o privada, edificio a edificio, con objeto de aprovechar el alto valor de situación, transformar su tradicional base residencial e incorporar el tejido urbano a un nuevo ciclo de explotación patrimonial. Y es que, en cierta medida, "hasta la propia rehabilitación urbana ha reproducido a veces la lógica de las operaciones inmobiliarias, expulsando a los vecinos y simplificando y especializando el tejido urbano resultante" (Naredo, 2010:24)

A confirmar esta estrategia viene a sumarse la creciente actividad del sector de la rehabilitación de viviendas, convenientemente rearmado para explotar el enorme potencial de viviendas vacías ubicadas en esta porción de la ciudad, merced a la Ley 8/2013, de 26 de junio, de rehabilitación, regeneración y renovación urbanas, y poco después al Real Decreto Legislativo 7/2015, de 30 de octubre, por el que se aprueba el texto refundido de la Ley de Suelo y Rehabilitación Urbana. Como se puede apreciar en la Tabla 2, el volumen de negocio en restauración y conservación, que en gran parte tiene como destino el centro urbano, y que había alcanzado en 2006 los 23600 millones de euros, el $15 \%$ del total de inversión, inició entonces un descenso hasta alcanzar los 16547 millones en 2014, con la particularidad de que, como consecuencia de la espectacular caída de la inversión en obra nueva, la restauración y conservación representa, ahora, el 56 \% del total residencial.

Tabla 2. Volumen de negocio de la construcción residencial (millones de euros)

\begin{tabular}{|c|c|c|c|c|c|}
\cline { 2 - 6 } \multicolumn{1}{c|}{} & Total Residencial & Obra nueva & $\begin{array}{c}\text { Restauración y } \\
\text { conservación }\end{array}$ & $\begin{array}{c}\text { \% Obra } \\
\text { nueva }\end{array}$ & $\begin{array}{c}\text { \% Restauración } \\
\text { y conservación }\end{array}$ \\
\hline 2002 & 90120,9 & 73335,1 & 16785,8 & 81,4 & 18,6 \\
\hline 2003 & 105489,4 & 86931,1 & 18558,3 & 82,4 & 17,6 \\
\hline 2004 & 112579,2 & 93420,2 & 19159,0 & 83,0 & 17,0 \\
\hline 2005 & 145004,1 & 123241,0 & 21763,0 & 85,0 & 15,0 \\
\hline 2006 & 157184,7 & 133572,9 & 23611,7 & 85,0 & 15,0 \\
\hline 2007 & 146478,0 & 125115,3 & 21362,7 & 85,4 & 14,6 \\
\hline 2008 & 112352,2 & 88090,7 & 24261,5 & 78,4 & 21,6 \\
\hline 2009 & 79546,5 & 60763,8 & 18782,6 & 76,4 & 23,6 \\
\hline 2010 & 62198,0 & 40408,4 & 21789,6 & 65,0 & 35,0 \\
\hline 2011 & 46660,3 & 23830,7 & 22829,6 & 51,1 & 48,9 \\
\hline
\end{tabular}




\section{Tabla 2. Continuación}

\begin{tabular}{|c|c|c|c|c|c|}
\hline & Total Residencial & Obra nueva & Restauración y & \% Obra & \% Restauración \\
\hline 2012 & 38479,2 & 17369,7 & 21 109,5 & 45,1 & 54,9 \\
\hline 2013 & 30247,5 & 13253,0 & 16994,5 & 43,8 & 56,2 \\
\hline 2014 & 29573,3 & 13026,1 & 16547,2 & 44,0 & 56,0 \\
\hline
\end{tabular}

Fuente: Observatorio de vivienda y suelo (MFOM, 2015)

El paisaje resultante refleja, en términos generales y en cada porción del mismo, la dualidad y contradicciones propias de las etapas de crisis y transformación urbana, es decir, de aquellos periodos en los que se fuerza la obsolescencia de parte de las permanencias urbanas (Álvarez Mora, 2016), a la espera de un nuevo ciclo renovador: calles peatonales y nuevo mobiliario en algunas áreas del centro revestidas de decorados para el turismo, plazas de vieja función comercial o estancial, ahora desnudas, desprovistas de mobiliario público y convertidas en lugares vacíos a la espera del despliegue de terrazas vespertino y nocturno frente a decenas de edificios completos abandonados en situación próxima a la ruina, bajos comerciales cerrados y arruinados por cese y cierre de negocios, que no pueden subsistir al perder su clientela tradicional y no poder afrontar una renovación para adaptarse a la nueva demanda regular u ocasional; desintegración de los viejos vecindarios y pérdida de la calidad de vida cotidiana en algunos barrios-parroquia del centro, frente a nuevas áreas de ocio, que vienen a forzar el último ciclo de explotación de algunos edificios, nuevos equipamientos -aparcamientos, espacios libres etc.- que rompen con la lógica del caserío tradicional para organizar su visita en horario adaptado al turismo urbano.

Y en conjunto, y salvo algunas referencias monumentales, ya sean calles reurbanizadas o edificios monumentales relativamente bien conservados, gran parte de la ciudad tradicional ha perdido de forma irreparable su carácter, su especificidad, ya que aunque se había dispuesto de una abundante legislación protectora de los Monumentos y de los Conjuntos Histórico Artísticos, esta era incompleta, "[...] dando lugar a nuevas construcciones en las proximidades de estos y en zonas destacadas de ciudades antiguas rompiendo su armonía" (López, 1976, p. 10). Como consecuencia habían ido surgiendo

por toda nuestra geografía, los edificios llamados de "arquitectura funcional", de simples estructuras y distribuciones, tanto en los nuevos barrios de ensanches en poblaciones, como en sus cascos antiguos, perdiendo éstas sus características y tipismo. Es de lamentar que, pasados unos años, estos edificios funcionales, que en gran parte son producto de una 'arquitectura de la comodidad' para quien los proyecta, los veremos tanto en las ciudades del norte como en las de Andalucía, Levante o Extremadura, intercalados entre típicas construcciones regionales llamadas a desaparecer (López, 1976, p. 10). 
Se ha creado con todo ello un conjunto que empaqueta todos sus estereotipos para proporcionar el consumo de impresiones predecibles, de rutinas escenográficas que esconden todas las patologías tras un nuevo y rutilante decorado urbano. El resultado es tan aparente como desesperanzador: todos los centros acaban siendo el mismo, amueblados del mismo modo, como peatonalizados e iluminados con una única memoria de calidades; los entornos de las catedrales y otros monumentos se revisten y adaptan para los nuevos e inesperados usos urbanos del centro: el suceder de bodas de las iglesias y catedrales, las calles-bar a cielo abierto y plazas-terraza de todas las ciudades, parcialmente privatizadas, han convertido a una gran parte de la ciudad tradicional en un conjunto de lugares consumibles según las rutinas de la ciudad actual que convierte al centro en el lugar al que ir, ocasionalmente, para participar de la experiencia de ciudad. Y este proceso es en buena medida irreversible, dado que la población que retorna a los viejos lugares del centro, a los centros del centro crecientemente aburguesados no lo hacen para aprovechar el valor de la proximidad tan propio de la ciudad histórica, la que fue en el pasado, sino para rentabilizar el valor de la centralidad, en competencia con la creciente terciarización vertical y volumétrica de las áreas en las que los PGOU o los PECH permiten la coexistencia de usos.

La dinámica regeneradora, que consiste en "dar nuevo ser a algo que degeneró, restablecerlo o mejorarlo", es consustancial a la ciudad entre milenios; ha requerido de un soporte legal de asimilación entusiasta y acrítica, tras los excesos del boom inmobiliario, y se ha acompañado de un fuerte incremento de los precios del suelo del centro urbano, y de un cambio en su perfil funcional, al dar cabida a una nueva generación de usos terciarios necesitados de centralidad, que operan conforme a la estrategia de tierra quemada, es decir, ocupando y arrasando todo vestigio de uso tradicional, de forma que, en lo sucesivo y en ese lugar, solo tenga cabida esa actividad u otras equivalentes, siempre que estén adaptadas a la funcionalidad y precio de los nuevos contenedores que se van construyendo o remodelando. El objetivo de estas operaciones no es tanto erradicar la pobreza, sanear o esponjar urbanísticamente el centro como se hace en Barcelona (Tapada-Berteli \& Arbaci, 2011), sino insertar nuevas actividades generadoras de riqueza explotando la centralidad y las nuevas pautas de consumo y ocio social, como se pone de manifiesto en las grandes operaciones de escala metropolitana ya ejecutadas: Bilbao Ría 2000, o en ejecución: MahouCalderón, o la denominada operación Canalejas en Madrid. Una operación concebida como una auténtica reconversión inmobiliaria que transformará, tras más de ocho años de pausa, siete grandes edificios del centro de Madrid, junto a la Puerta del Sol, en un hotel y apartahotel gestionado por Four Seasons, y un centro comercial de alto nivel (Ortiz, 2016).

De forma aparentemente contradictoria, en este proceso de destrucción deliberada y selectiva de la ciudad ha podido resultar determinante toda la estrategia conservacionista, protectora, vinculada a la legislación sobre el suelo o sobre el patrimonio histórico (Álvarez Mora, 2016). Y es que, la identificación de los elementos susceptibles de proteger facilitaba la intervención en el resto del 
patrimonio edificado, de forma que es habitual que coincidan durante algún tiempo dos grandes vacíos: edificios vacíos catalogados - de intervención compleja y costosa- y solares vacíos, recalificados para dar cabida a los nuevos usos urbanos reservados para ocupar los huecos que generaba, por exclusión, la ciudad catalogada.

Este es el paisaje de los muchos centros del centro; de lugares, ora abandonados o convertidos en guetos, ora renovados y regenerados (Tomé, 2007, 2016) que no pertenecen a sus vecindarios sino a los segmentos de clientela que los transita u ocupa apropiándose ocasionalmente de los valores de centralidad que proporcionan (López, 2016); centros que han convertido sus viejas tradiciones también en reclamos turísticos para asegurar una vitalidad - siquiera por tránsito- que ya no proporcionan sus escasos y renovados vecindarios por estancia o permanencia. Y paradójicamente, toda la imagen de la ciudad, su marca urbana, está anclada es estos lugares ora semivacíos, ora sobreocupados según los usos, ritmos y costumbres sociales reservados ahora a esta porción de la ciudad, a la vieja ciudad, regenerada, rodeada por múltiples e impersonales variantes de crecimiento por polígonos y nuevas e infinitas periferias.

\section{La ciudad polígono y el crecimiento por prolongación de alineaciones de la segunda mitad del siglo XX: entre el suburbio y las grandes barriadas populares}

Adosados a los viejos barrios extrarradio y sin solución de continuidad, se encuentra la segunda gran pieza del puzle urbano; es la que está conformada, esencialmente, por tres subconjuntos: en primer término, los grandes barrios de protección y de promoción pública y privada de los grandes planes de vivienda de segunda mitad del siglo XX en los que se fomentó mediante varias fórmulas de protección pública, el acceso a la vivienda en propiedad. ${ }^{3}$ En segundo lugar, por una serie de barriadas -entonces ultraperiféricas- autoconstruidas de forma ilegal o alegal, sobre suelo de titularidad pública o privada, parcelado o no, que fueron objeto de diversos programas de integración y regeneración desde finales de los años setenta del siglo XX; y finalmente, por las barriadas de los planes parciales de la segunda generación de planes parciales ejecutados en España hasta la sentencia del Tribunal Constitucional de 1997. Toda la política urbanística de este largo periodo estuvo centrada, en cierta medida, en el traslado ordenado hacia las primeras periferias, apoyándose en los grandes ejes de transporte público y también privado, y partiendo de la hipótesis de que las ventajas de accesibilidad y comunicación asociadas a estos ejes bastarían

3 El Real Decreto 233/2013, de 5 de abril, regula el Plan Estatal de fomento del alquiler de viviendas, la rehabilitación edificatoria y la regeneración y renovación urbana, 2013-2016. En él, y por primera vez, deja de promocionarse la vivienda en propiedad en favor del alquiler y la rehabilitación de la ciudad consolidada. 
para ejercer atracción sobre la población que decidía trasladarse a los márgenes, donde se concentraba la oferta de vivienda de alta densidad del periodo (Kagermeier, 2007, p. 86).

Se trata de un área de hiperespecialización residencial, sin concesión alguna a la sorpresa, hecha por repetición de tipos constructivos vagamente racionalistas, de construcción económica, necesitados ya de costosas operaciones de rehabilitación integral, regeneración o renovación, que tendrán que ser sufragadas, una vez más, con fondos públicos a tan sólo cuatro o cinco décadas de su ocupación. ${ }^{4}$ Este extenso y abigarrado sector presenta caracteres formales -urbanización y edificación- muy homogéneos, parcialmente singulares en función del momento y del Plan de vivienda al que pertenece, radicalmente opuestos a la primera acepción del término residencial del diccionario de la lengua de la RAE: "Dicho de un área urbana: Destinada principalmente a viviendas de cierta calidad"; y es que si algún rasgo es común a este sector en todas las ciudades españolas es su carácter popular, la esencia de barrio, ya que incorpora, a veces, todas las acepciones negativas del término, manifiestas en las expresiones el otro barrio -por el otro mundo-, andar de barrio - por andar de trapillo-, comercio de barrio o barriobajero, entre otros.

El carácter relativamente homogéneo de estas unidades, viene en gran parte dado por la forma en que se recoge en España la tradición organicista que, anclada en el siglo XIX y sistematizada en la primera mitad del siglo XX por el plan de New York o los planes de Londres o París -C. A. Perry, P. Abercrombie, G. Bardet, G. Dupont, etc.- consideraba factible ordenar el espacio urbano a partir de pequeños conjuntos ya fuesen neighbourhood unit, satellite towns, escalones territoriales, - la jerarquía desplegada en la construcción a partir de 1958 de los grands ensembles, y que comprendía: unidades vecinales (de 800 a 1500 viviendas), barrios (de 1500 a 2500 viviendas) y distritos (de 3000 a 6000 viviendas) o microdistritos, que desde los años veinte del siglo XX fueron base para la ordenación del crecimiento en las ciudades soviéticas.

Este modo de planear (ordenar) el crecimiento de la ciudad se recoge en España por algunos arquitectos y urbanistas desde los años cincuenta, siendo destacables las aportaciones de Gabriel Alomar Esteve y Miguel Duran Loriga, quienes, siguiendo la estela de otras escuelas europeas o norteamericanas, plantearon diversas propuestas sobre el tamaño de las unidades de convivencia elementales o unidades de vecindario, ya fuesen los 6000 habitantes del primero, o la más estructurada propuesta del segundo. Consideraba el primero que "desde el punto de vista de estricta convivencia social, el barrio no debería contener más de 500 familias, ya que estas representan el número máximo de vecinos que pueden conocerse más o menos personalmente y

4 En el periodo 1948-1973, es decir, en el periodo de mayor desarrollo de la política de vivienda y construcción de polígonos residenciales, se construyeron en España según datos del INE 2915677 viviendas protegidas: 246309 entre 1953 y 1957, 630959 entre 1958 y 1962. 1003345 entre 1963 y 1967 y, finalmente, 1035064 entre 1968 y 1973. 
desarrollar entre ellos relaciones primarias" (Alomar, 1961); y continuaba señalando que "el agrupamiento de tres o cuatro barrios puede constituir un distrito, pero éste será siempre una realidad puramente administrativa, nunca una realidad social". Con diferencias de nomenclatura, composición, tamaño y equipamiento de los subgrupos señalados, los diferentes planes de vivienda desde 1939 -subvencionadas, bonificables, renta reducida, limitada, plan nacional, etc.planteaban agrupaciones funcionales de diversa escala hasta que finalmente el Plan Nacional de la Vivienda 1961-1976 confirmó la organización del nuevo suelo de los planes en torno a tres unidades, con su correspondiente dotación de equipamientos: el núcleo residencial -5000 habitantes, 10 hectáreas-, la unidad de barrio -20 000 habitantes, 40 hectáreas-, y finalmente, la unidad de distrito -100000 habitantes, 250 hectáreas- (INV, 1962).

En todo caso, y con independencia del origen formal-administrativo al que correspondan, estos conjuntos, en una parte hoy auténticos barrios vulnerables atendiendo a los criterios empleados en el Atlas de la Vulnerabilidad Urbana en España, conforman una primera periferia que envuelve, en anodinos y alienantes recorridos, a la vieja ciudad tradicional, conformando un paisaje descarnado, de asfixiante densidad, tanto por las altas concentraciones de edificación o de población, como por la crónica carencia de equipamientos en origen, resuelta a partir de 1979 -primeros ayuntamientos democráticos- aunque de forma periférica, excéntrica en cada barrio, y de integración compleja (Ministerio de Fomento, 2011a). Es un sector de subgrupos con nomenclatura propia, barrios de edificación abierta y promoción unitaria (Rubio \& Molina, 2010), socialmente homogéneos en origen, y asiento ahora de una abigarrada estructura social en la que convive una ancho estrato de población muy envejecida, con aquellas segundas generaciones que quedaron atrapadas en el barrio y con grupos de población inmigrante vagamente ordenados por nacionalidades o etnias que, como consecuencia de la especulación y elevados alquileres, acaban por sobreexplotar la vivienda, hasta hacer aflorar fenómenos de tugurización propios de las ciudades españolas en los años cuarenta y cincuenta del siglo XX, hoy ya casi de carácter residual. El paradigma funcionalista que animó el origen de tales barrios puede ser una de las causas de la segregación social involuntaria y de la vulnerabilidad que es hoy característica dominante en ellos y que precisa de operaciones de regeneración o rehabilitación integral (Vorauer, 2011).

La omnipresencia de viejos vehículos aparcados en las estrechas calles de estos barrios, la pérdida de buena parte de la actividad comercial en parte de ellas, y la falta de alternativas a los casi únicos espacios de relación subsistentes, ya sean los pequeños fragmentos de parque-plaza, los centros de salud, la farmacia y las viejas tiendas de barrio o los supermercados, han acabado por apagar el destello de nueva vida urbana que en su día, en los estertores de la posguerra, estas áreas urbanas representaron para la nueva población urbana trabajadora; son los barrios que ahora ocupan una estratégica posición en el entramado urbano y que, tanto por razones sociales como patrimoniales, justifican su necesaria remodelación global aprovechando las figuras legales 
habilitadas para esta finalidad como las Áreas de Rehabilitación Integral (ARI) que tan óptimos resultados han producido ya algunas ciudades españolas como en el barrio de la Rondilla en Valladolid o del polígono Río Vena en Burgos, o el barrio de San Juanillo y el polígono Casas del Hogar -barrio del Carmen- en Palencia.

Al tratarse de áreas urbanizadas y edificadas ex novo, sin tradición anterior en el lugar ni grupos arraigados en él que pudieran desempeñar una labor educadora respecto a la convivencia en ellas, los grandes barrios de vivienda oficial se apropiaban del lugar a través de procedimientos de segregación más tarde denostados. Gabriel Alomar (1962, p. 124) indicaba en su Sociología Urbanística que

la efectividad social y urbanística del barrio se consigue por dos medios principales: la separación física entre los distintos barrios y el centro comunal actuando como foco de atracción. [El primer objetivo] se alcanzaría disponiendo de forma perimetral vías de tráfico veloz, a ser posible una vía parque, o al menos una calle muy ancha que no se convierta en calle comercial. [Y el segundo, precisaría de la construcción de] un Centro Comunal, que contuviera una parroquia, el centro social, algún edifico administrativo, el cine, la plaza en la que se celebren las fiestas locales, o el supermercado. [Este Centro Comunal será siempre un] punto focal que dará al barrio su personalidad y su propio paisaje urbano, contribuyendo a crear en la gente el espíritu de barrio que tan importante resulta para el desarrollo de la comunidad.

Concebidos los nuevos barrios con principios similares a los apuntados, la ciudad de este periodo era una ciudad por ello notablemente dividida y despersonalizada, suma de elementos mal soldados en origen con la ciudad tradicional, de promoción pública o privada, conformando grandes agregados de población obrera separados por la distancia física y social que impone, todavía, la vieja sociedad local (García Cuesta, 2000; Tatjer, 2005). Estos nuevos barrios eran la viva estampa de la desolación; conformados por bloques y más bloques de vivienda, calles mal asfaltadas y pobremente iluminadas en origen, y toda la vida no laboral organizada por la parroquia, un cine y la tienda de ultramarinos, así como un centro-ciudad para invadir los domingos con objeto de nutrir la experiencia de ciudad (Calderón, 2001). Parte de estos nuevos barrios se despoblaban los fines de semana de obligado retorno al pueblo donde habían quedado las raíces, mientras que los viejos barrios de lo que entonces era la ciudad se paseaban, como en el siglo XIX, por su plaza o su calle mayor.

La pérdida de valor patrimonial de estas áreas, suma de las secuelas de la crisis financieroinmobiliaria y de un incipiente proceso de tugurización, es perfectamente apreciable en la tipología de la cartera de inmuebles que han quedo atrapados en el pasivo de los bancos y cajas de ahorro; predominan en ella las viviendas de estos viejos barrios del desarrollismo ya sea porque sirvieron 
para avalar la compra de otro inmueble o ya porque fueron adquiridos por el sector de la demanda hipotecaria menos solvente -inmigrantes, bajos ingresos, trabajo precario etc.- que ha sido el primer afectado por la crisis. Y su vuelta al mercado es muy problemática ya que su desproporcionado valor de tasación sirvió para hipotecar a centenares de miles de familias que nutren ahora la relación de impagos y desahucios que caracteriza al sector; ${ }^{5}$ y sus calidades y las del entorno en que se ubican son tan bajas, tan subestandar, que sólo una sensible reducción del precio y su venta a los llamados fondos buitre haría viable su salida, algo que no cabe esperar de forma apreciable a corto plazo, por las condiciones de la economía y el mercado al finalizar la segunda década del siglo XXI.

Conforman el grueso del tejido residencial de la ciudad compacta (Campesino, 2014), cosido y colmatado años más tarde por pequeñas promociones de vivienda, edificio a edificio, de los planes y proyectos en suelo urbano o urbanizable de los años ochenta y noventa (ver Tabla 3). Según el censo de 2011, el 23,1 \% del parque edificado de viviendas principales se construyó entre 1951 y 1970, y sumado al construido entre 1971 y 1980 -el 21,1\%-, aportan casi el $45 \%$ del tejido edificado, en polígono o no, de la ciudad española. Son la experiencia de ciudad cercana para una parte sustancial de la población urbana española, están repartidas por todas las esquinas de la ciudad, pero no forman parte del imaginario de ella, como si se hubiesen concebido en forma de grandes espacios de reserva, espacios de los que escapar, en todas las pautas de comportamiento social o residencial en la ciudad, inducidas por el poderoso sector de la promoción inmobiliaria en España en las décadas -última y primera- del cambio de milenio. De ahí la progresiva depreciación del valor de cambio de las grandes barriadas de vivienda de los años cincuenta y sesenta del siglo XX, necesitadas de una profunda regeneración, y en su caso renovación o rehabilitación, y su rápida colonización en el proceso de marginalización (Campesino, 2014), y vulnerabilidad adquirida (Hernández, 2007) al que por obsolescencia están sometidas debido a la aceleración del proceso de filtering up.

Tabla 3. Viviendas principales según la antigüedad del edificio (\%)

\begin{tabular}{|c|c|c|c|c|c|c|c|c|c|c|}
\hline Período & $\begin{array}{c}\text { Antes de } \\
1900\end{array}$ & $\begin{array}{c}1901- \\
1920\end{array}$ & $\begin{array}{c}1921- \\
1940\end{array}$ & $\begin{array}{c}1941- \\
1950\end{array}$ & $\begin{array}{c}1951- \\
1960\end{array}$ & $\begin{array}{c}1961- \\
1970\end{array}$ & $\begin{array}{c}1971- \\
1980\end{array}$ & $\begin{array}{c}1981- \\
1990\end{array}$ & $\begin{array}{c}1991- \\
2001\end{array}$ & $\begin{array}{c}2002- \\
2011\end{array}$ \\
\hline $\begin{array}{c}\text { \% Viviendas } \\
\text { principales }\end{array}$ & 3,8 & 2,8 & 2,8 & 3,2 & 7,8 & 15,3 & 21,1 & 13,0 & 16,0 & 15,0 \\
\hline
\end{tabular}

Fuente: INE Censos de Población y Viviendas (2011)

Estos barrios de la ciudad polígono participan, en la actualidad, de una parte de los indicadores de vulnerabilidad de las áreas o barrios vulnerables españoles; en cierto modo, se pueden considerar

5 Según los datos del Consejo General del Poder Judicial (CGPJ), los procedimientos de desahucio solicitados ante los juzgados españoles alcanzaron un nuevo máximo histórico en el segundo trimestre del año 2011 al ascender a 16 464, un 21,2 \% más que el mismo período del año anterior (Agencia Efe, 2011). 
como una suma - de ponderación desigual- de tres variables: ancianos, emigrantes y jóvenes con trabajo precario y poder adquisitivo bajo o muy bajo. Desde el punto de vista de su génesis, presentan también alguna singularidad: no han sido barrios vulnerables en origen (ver Tabla 4), no se crearon como barrios degradados, como barrios de autoconstrucción o edificación precaria, sino que han ido adquiriendo esa condición - la vulnerabilidad-con el paso del tiempo (Rubio \& Molina, 2010), y como consecuencia también de los fenómenos de sucesión antes indicados, de la falta de inversión en el mantenimiento de la vivienda e infraestructuras de urbanización, de forma que, no siendo barrios autoconstruidos, son en la actualidad barrios auto-degradados e incluso políticamente marginados. ${ }^{6}$

\section{Tabla 4. Variantes tipológicas de origen y evolución de la ciudad polígono}

\begin{tabular}{|c|c|c|c|c|}
\hline Periodo & Tipología & Categoría & Subtipo & Evolución \\
\hline $\begin{array}{l}1940- \\
1960\end{array}$ & $\begin{array}{l}\text { Barrios autoconstruidos. } \\
\text { Suburbios }\end{array}$ & $\begin{array}{l}\text { Vulnerabilidad } \\
\text { de origen }\end{array}$ & $\begin{array}{l}\text { Barrios } \\
\text { degradados }\end{array}$ & $\begin{array}{l}\text { Eliminados-Renovados } \\
\text { Integrados- regenerados }\end{array}$ \\
\hline $\begin{array}{l}1950- \\
1970\end{array}$ & $\begin{array}{l}\text { Polígonos y grupos } \\
\text { viviendas subvencionadas }\end{array}$ & $\begin{array}{l}\text { Vulnerabilidad o } \\
\text { adquirida }\end{array}$ & $\begin{array}{l}\text { Barrios } \\
\text { vulnerables }\end{array}$ & $\begin{array}{l}\text { Degradados-abandonados } \\
\text { Integrados-renovados }\end{array}$ \\
\hline
\end{tabular}

Fuente: elaboración propia

Se trata, por otra parte, de extensas áreas de promoción pública y privada de carácter monofuncional, construidas con el único objetivo de proveer de vivienda de forma rápida y accesible. Su acelerado proceso de degradación, por ello, no puede afrontarse tan solo mediante políticas de edificio - rehabilitación, eficiencia energética, infraestructuras de edificación- (Rubio \& Molina, 2010), sino que precisan de operaciones más complejas con las que romper el estigma asociado a su hiperdensidad y tipología de vecindarios. Se necesita intervenir en el tejido que las soporta, para abrirlo en la medida que sea posible, insertar equipamientos de escala ciudad con los que quebrar la burbuja funcional y social asociada a su origen y evolución en los últimos 50 años. Para ello se precisa de estrategias que vayan más allá de la simple rehabilitación edificatoria, y por lo tanto, del concurso de todas las administraciones con interés en la ciudad en general, y especialmente en aquellos barrios en los que fue recluida, irremediablemente, apresuradamente, la generación de la postguerra tardía en los albores de los años sesenta del siglo XX.

Adosadas a estos barrios se encuentran algunas de las áreas de vieja industrialización, ubicadas a veces en la prolongación de alineaciones en alguna carretera de acceso, o bien de modo compacto en polígonos de los años sesenta o setenta, compartiendo espacio con algunos grandes equipamientos clásicos - pasillos ferroviarios y estaciones, cementerios, centros deportivos,

6 Véanse al respecto las consideraciones que recogen el Atlas de la Edificación Residencial en España 2001 y 2011 (Ministerio de Fomento, 2015) y el Atlas de la Vulnerabilidad Urbana en España 2001 y 2011 (Ministerio de Fomento, 2015). 
embrionarias áreas logísticas...-, o con fragmentos de tejido rural de secular y especulativo barbecho, dispersos entre alguno de los grandes paquetes de suelo urbano no consolidado que no llegaron a ser desarrollados y ocupados en el periodo de optimismo urbanizador de comienzos del siglo XXI.

Especial consideración tiene, en este segundo gran conjunto, uno de los fenómenos con mayor capacidad para alterar los grandes rasgos de la estructura de la ciudad: se trata del ferrocarril. Y es que, siglo y medio después, las ciudades vuelven a estar afectadas por procesos de vaciado y renovación de una parte de su tejido, para dar cabida a nuevos usos y nuevas centralidades apoyadas en los ingentes recursos que movilizará el mercado inmobiliario asociado a la explotación de las viajas áreas ferroviarias e industriales a ellas asociadas. Pero esa será una tarea que ocupará a varias generaciones, tanto por la envergadura de la obra como por las incertidumbres financieras y logísticas que afectan a todo el proceso.

Esta ciudad, compacta hasta los años noventa del siglo XX, perdía carácter y se difuminaba en los bordes, incorporando pequeños cambios cuantitativos en los usos del suelo hasta que se desdibujan y pierden gradualmente los caracteres urbanos, las propiedades de la ciudad: la vieja y la nueva, la compacta y la incipiente dispersa.

\section{Ordenar el territorio para desordenar el crecimiento: la nueva ciudad periferia}

La tercera unidad dotada de personalidad propia en la ciudad al final de las dos primeras décadas del siglo XX, es la que hemos denominado la ciudad de los grandes sectores de suelo urbanizable y planes parciales residenciales, y de colmatación de los intersticios de suelo urbano consolidado y no consolidado que fueron generándose en las décadas anteriores. Es una ciudad hecha de fragmentos de ciudad de grandes proporciones, conformando una porción nada desdeñable del tejido urbano destinado a vivienda construido en las tres últimas décadas (de 1981 a 2011), es decir, en el periodo de hipertrofia normativa padecido por el conjunto del sistema urbano durante el que se ordena el territorio urbano, desordenando con ello toda la lógica del crecimiento sostenible, sensato, necesario. A lo largo de este periodo se edificó el 44 por 100 del total de viviendas ocupadas según el censo de 2011, confirmando el salto cuantitativo que da la ciudad española en el último tercio del siglo XX (Brandis, 2007). Se estaba creando el nuevo territorio de los sueños, la nueva ciudad dormitorio, resultado de un crecimiento descomunal, de pesadilla, tan difícil de digerir que ha creado el tercer gran vacío urbano: los barrios-ciudad, "una suma de paisajes desolados, derivado del gran stock de viviendas vacías, suelo urbanizado y abandonado y ciudades desordenadas" (Méndez \& Plaza, 2016). 
Estos nuevos "barrios fantasma" son de creación reciente y están conformados en más de una quinta parte (el 21,4 \%) por viviendas vacías ubicadas en edificios construidos entre 2001 y 2011.

El número de viviendas vacías aumentó entre ambos censos en 336943 unidades -un incremento del 10,8 \%-, alcanzando en el último un total de 3443365 (ver Tabla 5); una cifra poco relevante en relación al problema que se analiza, ya que buena parte son viviendas vacías muy envejecidas, ubicadas en municipios muy pequeños, pero que es un indicador de las dimensiones globales del despilfarro inmobiliario en España. En lo tocante a la distribución municipal, es posible destacar, a partir de los datos del Censo de Viviendas de 2011, algunos fenómenos, tales como la reducción en el último periodo intercensal del número de viviendas vacías en algunas ciudades como Madrid $(-14,2 \%)$, Valencia $(-12,6 \%)$ y Barcelona $(12,4 \%)$; y en sentido contrario, el aumento de viviendas vacías fue espectacular en Murcia (60,8\%), Las Palmas (29,7 \%), Sevilla (10,3\%), Zaragoza $(8,8 \%)$ o Málaga $(7,5 \%)$.

Tabla 5. Viviendas vacías $2001-2011$ por comunidades autónomas

\begin{tabular}{|l|r|r|r|r|}
\hline & \multicolumn{1}{|c|}{$\begin{array}{c}\text { Viviendas } \\
\text { vacías } 2011\end{array}$} & \multicolumn{1}{c|}{$\begin{array}{c}\text { Viviendas } \\
\text { vacías } 2001\end{array}$} & $\begin{array}{c}\text { Diferencia } \\
2011-2001\end{array}$ & $\begin{array}{c}\text { Porcentaje } \\
\text { de viviendas } \\
\text { vacías }\end{array}$ \\
\hline Andalucía & 637221 & 548669 & 88552 & \multicolumn{1}{c|}{$18,5 \%$} \\
\hline Aragón & 100337 & 85716 & 14621 & $2,9 \%$ \\
\hline Asturias & 82857 & 72640 & 10217 & $2,4 \%$ \\
\hline Baleares & 71255 & 85535 & -14280 & $2,1 \%$ \\
\hline Canarias & 138262 & 138892 & -630 & $4,0 \%$ \\
\hline Cantabria & 47059 & 36518 & 10541 & $1,4 \%$ \\
\hline Castilla y León & 258451 & 209006 & 49445 & $7,5 \%$ \\
\hline Castilla-La Mancha & 202657 & 137900 & 64757 & $5,9 \%$ \\
\hline Cataluña & 448356 & 452921 & -4565 & $13,0 \%$ \\
\hline C. Valenciana & 505029 & 444823 & 60206 & $14,7 \%$ \\
\hline Extremadura & 105173 & 103506 & 1667 & $3,1 \%$ \\
\hline Galicia & 299396 & 229360 & 70036 & $8,7 \%$ \\
\hline Madrid & 263279 & 306556 & -43277 & $7,6 \%$ \\
\hline Murcia & 129117 & 95589 & 33528 & $3,7 \%$ \\
\hline Navarra & 35466 & 35102 & 364 & $1,0 \%$ \\
\hline País Vasco & 81003 & 94287 & -13284 & $2,4 \%$ \\
\hline Rioja, La & 35745 & 22898 & 12847 & $1,0 \%$ \\
\hline Ceuta & 1335 & 2817 & -1482 & $0,0 \%$ \\
\hline Melilla & 1367 & 3687 & -2320 & $0,0 \%$ \\
\hline TOTAL NACIONAL & 343365 & 3106422 & 336943 & $100,0 \%$ \\
\hline
\end{tabular}

Fuente: INE (2013)

Más relevante es el hecho de que buena parte de las viviendas vacías estén localizadas en municipios medios e incluso pequeños, próximos a las grandes aglomeraciones urbanas, 
confirmando el fenómeno de la dispersión del crecimiento por competencia intermunicipal en materia de precios de suelo y viviendas. En 2011, algunos de los municipios con mayor porcentaje de viviendas vacías en España eran Torrepacheco (Murcia) 35,9\%, Denia (Alicante) 31,3\%, Lalín (Pontevedra) 28,2\%, Manresa (Barcelona) 23,8 \%, o Morón de la Frontera (Sevilla) 22,7\%. Y es muy significativo a este respecto, que de los veinte municipios con un tamaño superior a 2000 habitantes y con un mayor porcentaje de viviendas vacías, siete fuesen de la provincia de Toledo, o que algunas ciudades de más de 20000 habitantes tuviesen, en 2011, más de una cuarta parte de sus viviendas sin ocupar incluyendo alguna capital de provincia como Ávila, y en términos generales diversos municipios ubicados dentro del área urbana de las grandes ciudades: Sevilla (Coq, 2012), Valencia (Gaja, 2015; Boira,2012).

Este tercer conjunto en la estructura urbana, de prolija nomenclatura - periferias, áreas suburbanas, periferias difusas, o diversas generaciones de coronas o cinturones metropolitanos- es un territorio esponja, poroso, lleno de huecos, y estructurado a partir de múltiples relaciones entrecruzadas en todas las direcciones. ${ }^{7}$ En unos casos son relaciones viarias -avenidas, rondas, tramos urbanos de autovías-autopistas-, en otros casos son funcionales coincidiendo con nuevos centros de actividad -cuñas o enclaves, polígonos industriales, centros de empresa, parques tecnológicos, plataformas, centros y zonas de actividad logística, puertos secos...-. Y en otros son dotacionales, con gran capacidad para convertirse en áreas de centralidad secundaria distribuidas según la lógica de la red viaria y desarrollo residencial adyacente de baja densidad -centros comerciales y de ocio, parques comerciales, hipermercados, hospitales, complejos deportivos y de ocio, centros de congresos, campos de golf...-. El conjunto de esta nueva ciudad fragmentada y porosa, dispersa, se completa finalmente con algunas grandes infraestructuras que, por su capacidad de atracción, articulan el tejido esponjoso - puertos, aeropuertos, intercambiadores de transporte, nuevos cementerios-parque, grandes parques y espacios libres- y con los nuevos cinturones verdes de la ciudad opulenta como son las múltiples variantes de suelo protegido que blindan a las urbanizaciones cerradas y exclusivas que supieron anticiparse al periodo protector abierto en España, en términos urbanísticos, con la ley de Suelo de 2007.

Porque, desde hace algunas décadas, la urbanización, otrora contenida, se difuminó en sus bordes, ocupando áreas cada vez más extensas, forman do auténticos archipélagos, o lugares temáticos idénticos en todas las partes del mundo, localizados cada vez más lejos, como si tuviésemos nuevos e ilimitados territorios para conquistar y nuevos e ilimitados recursos para consumir. Este modelo, amparó a su vez conductas de tipo pionero en la ocupación del territorio,

7 El diccionario de la RAE define el término esponja como "Esqueleto de ciertos espongiarios, formado por fibras córneas entrecruzadas en todas direcciones, y cuyo conjunto constituye una masa elástica llena de huecos y agujeros que, por capilaridad, absorbe fácilmente los líquidos". 
apoyadas en el eslogan -más lejos, más suelo, más caro, más homogéneo-. Y es que, "en el urbanismo se ha impuesto el modelo de la conurbación difusa y en la construcción el estilo universal" (Naredo, 2010), a tal punto que los nuevos modelos urbanos y constructivos, lejos de mejorar los anteriores, los han destruido o engullido. En cierta medida, como señala Ribas i Piera, la estructura y forma de la ciudad contemporánea corresponde a lo que se llamó Regional City o Cittá-Territorio, y que hoy se acostumbra a llamar ciudad difusa; un modelo que se caracteriza por su mayor dimensión respecto a la ciudad tradicional y, por tanto, "por englobar, en su vasta extensión, no sólo los paisajes edificados, sino también grandes espacios libres con sus paisajes mal llamados naturales" (Ribas i Piera, 2004).

El espacio así descrito, en realidad no debería contemplarse exclusivamente como la periferia de una ciudad o como un elemento sin más de una estructura urbana, definida por sus perfiles dominantes como hemos hecho hasta ahora. Antes al contrario, cada uno de esos subconjuntos opera o puede operar como una nueva variante de ciudad a la que denominamos ciudad periferia; una ciudad aparentemente inacabada, hiperespecializada en alguna función -ciudad del transporte, ciudad financiera, ciudad de la justicia- aunque contenga otras funciones complementarias o subsidiarias. De este modo, el tercer componente de la estructura ya no es el espacio de la ciudad compacta, simplemente prolongado. Es, en realidad, la suma de muchas y variadas formas de ciudad periferia, de ciudad de ciudades (Roca, Arellano \& Moix, 2011; Nel.lo, 1998; Mas, 1999; López de Lucio, 2004) a las puertas de lo que había sido en el pasado la ciudad de un solo centro, que todavía sigue aportando, a pesar de todo, la síntesis de toda experiencia de ciudad, parcialmente recreada en aquellos contenedores -centros comerciales cerrados o a cielo abierto- creados para el simulacro de la vida urbana (Martínez, 2015), en los que ésta se presenta idealizada y libre de las amenazas y riesgos de la vida real.

Algunos autores han demostrado que tales conjuntos ya no son, como en el pasado, meras concentraciones de empleo, o simples conglomerados residenciales. Por el contrario, estos vastos fragmentos de ciudad periferia, en los que se maximiza la relación densidad-tiempo, "[...] presentan características más acordes con lo que se esperaría fuese un subcentro en el paradigma del modelo de metrópolis mediterráneas, tales como la nodalidad, la diversidad, e incluso la especialización en actividades centrales -entendida como la concentración relativa de actividades direccionales con amplios rangos de mercado-" (Marmolejo \& Cerdá, 2012). Es, en definitiva, la ciudad inconclusa (Brandis, 2012) que algunos autores han descrito como una suma de "grandes actuaciones residenciales aisladas, diseñadas desde presupuestos de autonomía y, por tanto, empeñadas en reproducir sus propios elementos de centralidad a la vez que unos límites nítidos" (López de Lucio, 2004). 
No menos importante en este periodo, durante el que se conforma el que hemos identificado como tercer gran conjunto de la estructura urbana, es la intensidad con la que se traslada este crecimiento a los municipios colindantes con la ciudad -su área urbana-metropolitana-, exacerbando todos los defectos del crecimiento de la ciudad principal, al añadir algunas variables especialmente relevantes, tales como un menor rigor urbanístico, el interés municipal por crecer a costa de la ciudad principal y adquirir parte de sus atributos, la necesidad de competir mediante desproporcionadas reservas de suelo para vivienda, equipamientos comerciales o grandes dotaciones urbanísticas de escala regional, entre otras (Romero, 2010).

Tras la crisis, el paisaje de vacíos característico de la periferia urbana se amplifica al añadirse centenares de sectores de suelo urbanizable sin desarrollar o urbanizados, pero sin edificar, pertenecientes a los pequeños municipios del entorno de la ciudad central. Un análisis realizado en 2011 en 79 ciudades, capitales de provincia y municipios de más de 100000 habitantes, sobre los ámbitos o sectores de uso residencial que figuran en la base de datos del Sistema de Información Urbana (SIU), en el que se seleccionaban todos los sectores que promovían individualmente más de 1000 viviendas y que estuviesen desarrollados en menos del $70 \%$, ponía de manifiesto las verdaderas dimensiones del problema inmobiliario creado en España entre 1990 y 2007.

Como se puede apreciar en la Tabla 6, en 2011 existían en España 699 sectores, con capacidad para más de un millón y medio de viviendas, y 230 millones de metros cuadrados de edificabilidad prevista. A mayor abundamiento, y para corroborar las dimensiones del despilfarro, en el mencionado informe se destacaba el hecho de que "[...] la superficie media de suelo por sector es de 71,5 hectáreas, y el número previsto de viviendas era de 2409 unidades, lo que arroja una densidad vivienda -en los sectores de uso predominante residencial- de 46 viviendas por hectárea" (Ministerio de Fomento, 2011b). Un ejemplo sobresaliente de las características del modelo propuesto en el que son destacadas una oferta desproporcionada de suelo, la dispersión y baja densidad, y que justifica con creces su fracaso, así como el cambio de paradigma que consagra la ley de 2013 sobre Rehabilitación, Regeneración y Renovación urbanas.

Tabla 6. Sectores residenciales en España (2011)

\begin{tabular}{|l|r|r|r|}
\hline $\begin{array}{l}\text { Comunidad } \\
\text { Autónoma }\end{array}$ & $\begin{array}{r}\text { Número de } \\
\text { sectores }\end{array}$ & $\begin{array}{r}\text { Viviendas } \\
\text { previstas }\end{array}$ & $\begin{array}{r}\text { Edificabilidad } \\
\text { prevista }\left(\mathbf{m}^{2}\right)\end{array}$ \\
\hline Andalucía & 178 & 353496 & 58515311 \\
\hline Aragón & 6 & 16780 & 2069938 \\
\hline Asturias & 19 & 37177 & 4790636 \\
\hline Baleares & 6 & 17920 & 2329340 \\
\hline Canarias & 13 & 22798 & 2903105 \\
\hline Cantabria & 7 & 10240 & 1307545 \\
\hline Castilla y León & 79 & 144154 & 18740069 \\
\hline Castilla-la Mancha & 41 & 106384 & 17206092 \\
\hline Cataluña & 49 & 106368 & 16146331 \\
\hline
\end{tabular}


Tabla 6. Continuación

\begin{tabular}{|l|r|r|r|}
\hline $\begin{array}{l}\text { Comunidad } \\
\text { Autónoma }\end{array}$ & $\begin{array}{r}\text { Número de } \\
\text { sectores }\end{array}$ & $\begin{array}{r}\text { Viviendas } \\
\text { previstas }\end{array}$ & $\begin{array}{r}\text { Edificabilidad } \\
\text { prevista }\left(\mathbf{m}^{2}\right)\end{array}$ \\
\hline Com. Valenciana & 73 & 167703 & 22779818 \\
\hline Extremadura & 34 & 59641 & 8101558 \\
\hline Galicia & 16 & 48690 & 5446889 \\
\hline Madrid & 94 & 420104 & 59865716 \\
\hline Murcia & 5 & 9772 & 1312735 \\
\hline Navarra & 9 & 15938 & 2647591 \\
\hline País Vasco & 22 & 39326 & 4936346 \\
\hline Rioja, La & 8 & 10894 & 1309403 \\
\hline TOTAL & 659 & 1587385 & 230408423 \\
\hline
\end{tabular}

Fuente: Ministerio de Fomento (2011b)

Este proceso ha contribuido a ampliar el radio de influencia de la ciudad, a tal punto que las nuevas periferias ya no están asentadas sobre el término de la ciudad de mayor tamaño, sino que son la suma de las dinámicas de crecimiento de otras ciudades vecinas, de la localización de los diversos usos del suelo y de las relaciones funcionales que esa distribución territorial origina. Se trata de una suerte de descentralización concentrada, (Kagermeier, 2007), es decir, del impulso de una red de centros intermedios tributarios de la ciudad principal, que permitían una mejor distribución territorial de las actividades a costa de un incremento del tráfico rodado entre las periferias y la ciudad central por motivos de trabajo. En el mismo sentido, la proximidad de estos núcleos a las principales ciudades, la mayor disponibilidad de suelo para su crecimiento urbano y la menor repercusión de ese suelo en el precio final de la vivienda, hicieron que una parte de la población los eligiesen como lugar de residencia, al tiempo que en muchos casos trabajan, escolarizan a sus hijos, realizan sus compras y consumen su tiempo de ocio, en la ciudad central.

\section{Conclusiones: una ciudad llena de vacíos}

Desde una perspectiva geográfica, es decir, considerando formas y relaciones en el territorio, tres son los rasgos que presenta la ciudad española, no como impresión del momento, sino como trasunto de muchas décadas, coyunturas y estrategias de intervención en ella: en primer lugar que, como sociedad opulenta, ha acabado por asumir el despilfarro urbano, hasta tal punto que tienen tanto carácter vertebrador los vacíos como los espacios ocupados. En segundo lugar, que la ciudad sigue contemplándose como un territorio ocupado frente a otras divisiones administrativas del territorio, de forma que el motor del desarrollo ha sido y es la competencia y no la cooperación. Finalmente, que el territorio de la ciudad está permanentemente forzado a transformarse en función de la rentabilidad que cada ciclo de crecimiento, o paradigma impone, convirtiéndose en un mecanismo excluyente para usos y grupos cuyas necesidades han de atenderse, de forma remedial, mediante incentivos a la rehabilitación o estrategias equivalentes. 
Y si se reflexiona detenidamente sobre los tres grandes conjuntos analizados, en realidad, lo que caracteriza a las ciudades es la proporción del despilfarro, la entidad de los vacíos que el crecimiento ha generado: uno por envejecimiento del patrimonio edificado, que ora se recupera lentamente por su alto coste, ora se regenera de forma traumática para llenar con nuevos usos el vacío que deja la desnaturalización de la ciudad tradicional; otro por abandono ligado a su ínfima calidad -que se reutiliza por segmentos sociales con menor poder adquisitivo-; y un tercero, localizado en los nuevos planes parciales residenciales, que ha sido generado por la incapacidad para ocuparlo, como consecuencia de la crisis económica del primer decenio del siglo XXI. Un vacío éste que tiene un considerable valor estratégico para el mercado, ya que todavía en 2011 nada menos que el 21,4\% de las viviendas vacías se localizaban en edificios que habían sido construidos en los diez años anteriores a la realización del censo del citado año, confirmando su entidad, y por ende, la magnitud del despilfarro.

Declaración responsable: Las/os autoras/es declaran que no existe ningún conflicto de interés en relación a la publicación de este artículo. Los firmantes de este artículo son autores de forma conjunta e indiferenciada de la totalidad del artículo. 


\section{Bibliografía}

Agencia Efe (2011, Octubre 7). Adicae exige al Gobierno medidas urgentes ante el récord de desahucios. Diario El Mundo. Retrieved from

http://www.elmundo.es/elmundo/2011/10/07/suvivienda/1317998931.html

Alba Sargatal, Ma. (2001). Gentrificación e inmigración en los centros históricos: el caso del Raval de Barcelona. Scripta Nova, 94(66). http://www.ub.edu/geocrit/sn-94-66.htm

Alomar, G. (1961). Sociología urbanística. Madrid: Aguilar.

Alvarez Mora, A. (2016). Las prácticas de la conservación patrimonial como inductoras de la degradación, el abandono y la ruina. In F. Manero, \& J. L. García Cuesta (Coord.), Patrimonio cultural y desarrollo territorial (pp. 159-189). Madrid: Thomson Aranzadi.

Boira, J. V. (2012). Dinámica inmobiliaria, suelo y población en la ciudad de Valencia, 1960_ 2009. Scripta Nova, XVI(406). http://www.ub.edu/geocrit/sn/sn-406.htm

Brandis, D. (2007). Los espacios residenciales españolas en el cambio de siglo. En C. Delgado Viñas, M. Frochoso Sánchez, R. González Pellejero, E. González Urruela, A. Meer Lecha-Marzo, L. Puente Fernández, \& P. Reques Velasco (Coords.), Espacios públicos, espacios privados. Un debate sobre el territorio (pp. 25-53). Bilbao: AGE y Universidad de Cantabria.

Brandis, D. (2012). Los grandes desarrollos residenciales de la periferia de Madrid: de la burbuja a la crisis inmobiliaria. In C. Delgado Viñas, J. Juaristi Linacero, \& S. Tomé Fernández (Eds.), Ciudades y paisajes urbanos en el siglo XXI (pp. 241-262). Santander: Estudio.

Brandis, D., del Rio, I., \& Morales, G. (2016). Estudios de geografía urbana en tiempos de crisis. Territorios inconclusos y sociedades rotas en España. Madrid: Biblioteca Nueva.

Burriel de Orueta, E. (2008). La década prodigiosa del urbanismo español (1997-2006). Scripta Nova, XII(270). http://www.ub.edu/geocrit/sn/sn-270/sn-270-64.htm

Calderón Calderón, Basilio (2001). Una ciudad entre dos planes: planeamiento y cambio urbano en Valladolid 1970-1983. In E. Berzal de la Rosa (Coord.), Crónica de Valladolid 1936-2000 (pp. 316-328). Valladolid: El Mundo. http://uvadoc.uva.es/handle/10324/8535

Calderón Calderón, Basilio (2003). El paisaje de la ciudad histórica española en el cambio de siglo. Entre el renacimiento y la invención de la memoria. In B. Bernal Santaolalla (Coord.), El medio ambiente urbano en las ciudades históricas (pp. 17-42). Burgos: Secretariado de Publicaciones Universidad de Burgos.

Calderón Calderón, Basilio (2012). Del centralismo a la hipertrofia normativa regional: 1990-2010. Nuevas leyes para ordenar la ciudad. In M. Valenzuela Rubio (Coord.), El impacto del modelo 
autonómico en las ciudades españolas. Una aproximación interdisciplinar (pp. 57-96) Madrid: UAM.

Calderón Calderón, B., \& Garcia Cuesta J. L. (2014). Capitalidad política regional y cambios en la estructura urbana de Valladolid (1987-2012). Revista Estudios Geográficos, 75(276), 91-138

Campesino, A. (2014). Centros y periferias urbanas: ordenación y desgobierno. In R. Lois, \& A. Miramontes (Eds.), Reflexiones sobre las ciudades y el sistema urbano en tiempos de crisis (pp. 91-120). La Coruña: Universidad de Santiago de Compostela.

Capel, H. (2016). La forma urbana en la ciudad postcapitalista. Biblio3W, XXI(1177). hittp://www.ub.es/geocrit/b3w-1177.pdf

Cebrián Abellán, F. (2007). Ciudades con límites y ciudades sin límites. Manifestaciones de la ciudad difusa en Castilla-la Mancha. Boletín de la Asociación de Geógrafos Españoles, 43, 221240. http://www.age-geografia.es/ojs/index.php/bage/article/view/589/543

Coq Huelva, D. (2012). Crecimiento suburbano difuso y sin fin en el Área Metropolitana de Sevilla entre 1980 y 2010. Algunos elementos explicativos. Scripta Nova, XVI(397). hitp://www.ub.edu/geocrit/sn/sn-397.htm

Delgado Bujalance, B., \& García García, A. (2009). Una aproximación a los nuevos paisajes de la metápolis en Andalucía. Scripta Nova, XIII(297). http://www.ub.es/geocrit/sn/sn-297.htm

Delgado Viñas, C. (2016). Miradas sobre la ciudad desde la Geografía, la Historia y el urbanismo. Revista Ciudades, 19, 117-142.

Díaz Parra, I. (2014). La gentrificación, un regreso a la ciudad de la intervención urbanística. Boletín de la Asociación de Geógrafos Españoles, 64, 321-340. hitp://www.agegeografia.es/ojs/index.php/bage/article/view/1700/1617

Fernandez García, A. (2003). Las pautas del crecimiento urbano posindustrial: de la rururbanización a la ciudad difusa. Ería, 60, 88-

92. http://www.unioviedo.es/reunido/index.php/RCG/article/view/1438/1354

Gaja i Díaz, F. (2015). Reparar los impactos de la burbuja constructora. Scripta Nova, XIX(517). http://www.ub.edu/geocrit/sn/sn-517.pdf

Garcia Cuesta, J. L. (2000). De la urgencia social al negocio inmobiliario. Promoción de viviendas y desarrollo urbano en Valladolid (1960-1992). Valladolid: Ayuntamiento de Valladolid y Universidad de Valladolid.

García Fernández, J. (1974). Crecimiento y estructura urbana de Valladolid. Barcelona: Libros de la Frontera. 
García Fernández, J. (2000). Valladolid. De la ciudad a la aglomeración. Barcelona: Ariel.

INE (Instituto Nacional de Estadística) (2013). Notas de prensa. Censos de Población y Viviendas 2011. Edificios y viviendas. Datos provisionales. Retrieved from hitp://www.ine.es/prensa/np775.pdf

INV (Instituto Nacional de la Vivienda) (1962). Plan Nacional de la Vivienda 1961-1976. Madrid: INV.

Kagermeier, A. (2007). Estructura urbana y movilidad vial. Un estudio empírico sobre la zona sur del Estado de Baviera. Madrid: Comunidad de Madrid.

Lois, R. C., Piñeira M. J., \& Vives, S. (2016). El proceso urbanizador en España (1990-2014): una interpretación desde la geografía y la teoría de los circuitos de capital. Scripta Nova, XX(539). hitp://www.ub.edu/geocrit/sn/sn-539.pdf

López, M. A. (2016, 17 Octubre). El 40 \% de los edificios públicos del casco histórico de Segovia están en desuso. El Norte de Castilla. Retrieved from hitp://www.elnortedecastilla.es/segovia/201610/17/edificios-publicos-casco-historico20161016213855.html

López de Lucio, R. (2004). Morfología y características de las nuevas periferias. Nueve paisajes residenciales de la Región Urbana de Madrid. Urban, 9, 56-80.

Marchena Gómez, M. J., \& Hernández Martínez, E. (2016). Sevilla en la primera década del siglo XXI: transformaciones urbanas hacia un nuevo modelo de ciudad. Boletín de la Asociación de Geógrafos Españoles, 70, 393-417.

http://www.age-geografia.es/ojs/index.php/bage/article/view/2246/2133

Marmolejo, C., \& Cerda, J. (2012). La densidad-tiempo: otra perspectiva de análisis de la estructura metropolitana. Scripta Nova, XVI(402). http://www.ub.edu/geocrit/sn/sn-402.htm

Martínez Lorea, I. (2015). Nuevas privatopías urbanas. Estrategias ciudadanistas del espacio público. Ciudades, 18, 81-102.

Mas Hernández, R (1999). Periferias urbanas y nuevas formas espaciales. In R. Domínguez (Coord.), La ciudad. Tamaño y crecimiento (pp. 201-233). Málaga: Asociación de Geógrafos Españoles.

Mata Olmo, R. (2007, Septiembre 25). Auge inmobiliario y evolución de los usos del suelo en España. Por una nueva cultura del territorio (Resumen de conferencia inaugural). Retrieved from https://nuevaculturadelterritorio.files.wordpress.com/2008/08/nueva-cultura-territorio_rafamata.pdf 
Méndez Gutiérrez Del Valle, R., \& Plaza Tabasco, J. (2016). Crisis inmobiliaria y desahucios hipotecarios en España: una perspectiva geográfica. Boletín de la Asociación de Geógrafos Españoles, 71, 99-127.

Ministerio de Fomento (2010). Infraestructura de datos espaciales de España. Retrieved from http://www.idee.es/web/guest/europeo-inspire

Ministerio de Fomento (2011a). Atlas de la vulnerabilidad urbana. Retrieved from hHp://www.fomento.es/MFOM/LANG_CASTELLANO/DIRECCIONES_GENERALES/ARQ _VIVIENDA/SUELO_Y_POLITICAS/OBSERVATORIO/Atlas_Vulnerabilidad_Urbana/default.htm

Ministerio de Fomento (2011b). Sectores residenciales en España, 2011. Estudio sobre la Situación Actual de Ámbitos o Sectores con especial potencialidad edificatoria incluidos en el Sistema de Información Urbana (SIU). Madrid: Dirección General de Suelo y Políticas Urbanas. Retrieved from https://www.fomento.gob.es/VIVIENDA/201112_SectoresResidenciales2011.pdf

Ministerio de Fomento (2015a). Atlas de la Edificación Residencial en España 2001 y 2011. Metodología, contenidos y créditos. Retrieved from

hHp://www.fomento.es/MFOM/LANG_CASTELLANO/DIRECCIONES GENERALES/ARQ VIVI ENDA/SUELO_Y_POLITICAS/OBSERVATORIO/AtIEdiResEsp/

Ministerio de Fomento (2015b). Atlas de la Vulnerabilidad Urbana en España 2001 y 2011. Metodología, contenidos y créditos. Retrieved from

https://www.fomento.gob.es/MFOM/LANG_CASTELLANO/DIRECCIONES_GENERALES/ARQ _VIVIENDA/SUELO_Y_POLITICAS/OBSERVATORIO/Atlas_Vulnerabilidad_Urbana/

Ministerio de Fomento (2017a). Estudios y Publicaciones. Retrieved from

http://www.fomento.gob.es/MFOM/LANG_CASTELLANO/DIRECCIONES_GENERALES/ARQ VIVIENDA/SUELO_Y_POLITICAS/ESTUDIOS/

Ministerio de Fomento (2017b). Vivienda y actuaciones urbanas - Información estadística. Retrieved from http://www.fomento.gob.es/MFOM/LANG_CASTELLANO/ATENCION_CIUDADANO/IN FORMACION_ESTADISTICA/Vivienda/Estadisticas/default.htm

Naredo, J. M. (2010). "El modelo inmobiliario español y sus consecuencias". Boletín CF+S, 44, 13-27. http://habitat.aq.upm.es/boletin/n44/ajnar.html

Nel.lo, O. (1998). Los confines de la ciudad sin confines. Estructura urbana y límites administrativos de la ciudad difusa. In F. G. Monclús (Ed.), Urbanismo, ciudad, historia I. La ciudad dispersa. Suburbanización y nuevas periferias (pp. 35-57). Barcelona: Centro de Cultura Contemporánea de Barcelona. 
Ortiz, I. (2016, 31 Mayo). Visita a las tripas del proyecto Canalejas de Madrid. Diario El Mundo. Retrieved from http://www.elmundo.es/blogs/elmundo/entorno-habitable/2016/05/31/visita-alas-tripas-del-proyecto.html

Ponce Herrero, G. (2013). Estrategias de metropolización de la ciudad de Valencia en la etapa autonómica: la centralidad cuestionada en el modelo postchristaller de ordenación del territorio. Boletín de la Asociación de Geógrafos Españoles, 62, 147-172. hitp://www.agegeografia.es/ojs/index.php/bage/article/view/1573/1493

Precedo, A., \& Mínguez, A (2014). Una radiografía de las ciudades españolas: una evaluación del modelo postindustrial. In R. Lois, \& A. Miramontes (Eds.), Reflexiones sobre las ciudades y el sistema urbano en tiempos de crisis (pp. 15-73). A Coruña: Universidad de Santiago de Compostela.

Ribas i Piera, M. (2004). El paisaje y el urbanismo contemporáneo. Cartas Urbanas, 9, 32-37.

Roca Cladera, J., Arellano Ramos, B., \& Moix Bergadà, M. (2011). Estructura urbana, policentrismo y 'sprawl'. Los ejemplos de Madrid y Barcelona. Ciudad y territorio: Estudios territoriales, 168, $299-321$.

Romero, J. (2010). Construcción residencial y gobierno del territorio en España de la burbuja especulativa a la recesión. Causas y consecuencias. Cuadernos Geográficos de la Universidad de Granada, 47, 17-46.

Romero, J., Brandis, D., \& Melo, C. (2015). El giro neoliberal de las políticas para la ciudad en España. Balance a partir de los ejemplos de Madrid y Valencia. Boletín de la Asociación de Geógrafos Españoles, 69, 369-386.

Rubio, J., \& Molina, P. (2010). Estrategias, retos y oportunidades en la rehabilitación de los polígonos de vivienda construidos en España entre 1940 y 1980. Revista Ciudades, 13, 15-37.

Salingaros, N.A. (2005). Principles of Urban Structure (Design/science/planning). Amsterdam: Tecne Press.

Salom Carrasco, J. (2011). Procesos territoriales y transformaciones recientes del sistema urbano valenciano. Scripta Nova, XV(356). http://www.ub.edu/geocrit/sn/sn-356.htm

Santos Preciado, J. M. (2016). Metodología para medir la estructura urbana de la ciudad actual, utilizando la base de datos del catastro. Aplicación al sector suroeste de la comunidad de Madrid. Boletín de la Asociación de Geógrafos Españoles, 67, 37-60. http://www.agegeografia.es/ojs/index.php/bage/article/view/1816/1732

Soria-Lara J. A., \& Valenzuela Montes, L. M. (2014). Más allá de la estructura urbana y del patrón de viaje. El "entorno de movilidad" como instrumento para la planificación y la evaluación. Boletín 
de la Asociación de Geógrafos Españoles, 64, 273-296. hitp://www.agegeografia.es/ojs/index.php/bage/article/view/1698/1615

Tapada-Berteli, M. T., \& Arbaci, S (2011). Proyectos de regeneración urbana en Barcelona contra la segregación socioespacial (1986-2009): ¿̇solución o mito? Revista ACE, 17. hitp://hdl. handle.net/2099/11085

Tatjer, M. (2005). La vivienda obrera en España de los siglos XIX y XX: de la promoción privada a la promoción pública (1853-1975). Scripta Nova, IX(194)(23). http://www.ub.edu/geocrit/sn/sn-194-23.htm

Tome, S. (2007). Los centros históricos de las ciudades españolas. Eria, 72, 75-88.

Tome, S. (2016). Los centros históricos a debate: vistas cruzadas desde Oviedo. In F. Manero, \&J.

L. García Cuesta (Coord.), Patrimonio cultural y desarrollo territorial (pp. 237-275). Madrid: Thomson Aranzadi.

Vorauer, M. (2011). Las 3.000: segregación social en el espacio urbano. Sevilla: Universidad de Sevilla. 